\title{
Finite element and coupled finite element/smooth particle hydrodynamics modeling of the quasi-static crushing of empty and foam-filled single, bitubular and constraint hexagonal- and square-packed aluminum tubes
}

\author{
L. Aktay ${ }^{\text {a }}$, B.-H. Kröplin ${ }^{\text {b }}$, A.K. Toksoy ${ }^{\text {c }}$, M. Güden ${ }^{\text {c,* }}$ \\ ${ }^{a}$ German Aerospace Center, Institute of Structures and Design, Pfaffenwaldring 38-40, 70569 Stuttgart, Germany \\ ${ }^{\mathrm{b}}$ Institute of Statics and Dynamics of Aerospace Structures, University of Stuttgart, Pfaffenwaldring 27, 70569 Stuttgart, Germany \\ ${ }^{c}$ Department of Mechanical Engineering and Center for Materials Research, Izmir Institute of Technology, Gulbahce Koyu, Urla, Izmir, Turkey
}

Received 23 November 2006; accepted 28 March 2007

Available online 20 April 2007

\begin{abstract}
The quasi-static axial crushing behavior of empty and Al and polystyrene foam-filled Al single, bitubular and multi-tube-packed (hexagonal and square packing) configurations were investigated experimentally and numerically. Tubes were modeled using finite element and coupled finite element/smooth particle hydrodynamics. The numerical specific absorbed energy (SAE) values, deformation patterns, load values and number of folds formed were found to show agreements with those of experiments. Among the tested tube configurations only hexagonal- and square-packed empty tube designs showed increased SAE values over that of single empty tube. Furthermore, foamfilled multi-tube designs both hexagonal- and square-packed designs were found energetically more efficient than Al foam-filled single tubes at similar foam filler densities. The increased SAE values of multi-tubes were attributed to the frictional forces of the multi-tube designs and constraining effect of the die walls accommodating the tubes.
\end{abstract}

(C) 2007 Elsevier Ltd. All rights reserved.

Keywords: Crashworthiness; Energy absorption; Crushing; Foam filling; Aluminum foam; Energy absorbers

\section{Introduction}

Novel geometrical designs including the filling of tubular structures with lightweight metal and polymer foams have recently been taken considerable interest. Santosa et al. [1] investigated, experimentally and numerically, the axial crushing behavior of lightweight $\mathrm{Al}$ foam- and $\mathrm{Al}$ honeycomb-filled square box columns at quasi-static rates. It was found that although honeycomb filling of box columns was more weight efficient in compression, it was less efficient than $\mathrm{Al}$ foam filling in compression-bending load-

\footnotetext{
${ }^{*}$ Corresponding author. Tel.: +90 232 7507816; fax: +90 2327507890.

E-mail address: mustafaguden@iyte.edu.tr (M. Güden).
}

ing. A study on the bending collapse of thin-walled prismatic columns filled with $\mathrm{Al}$ foam and $\mathrm{Al}$ honeycomb further showed that columns filled with honeycomb and foam were more efficient in terms of specific absorbed energy (SAE) than the thickening of the column wall [2]. Børvik et al. [3] noticed that during a crash event the crushing load was neither pure axial nor pure bending but rather a combination of two and conducted a series of axial and oblique quasi-static loading tests on the empty and $\mathrm{Al}$ foam-filled tubular columns. It was shown by the same authors that the peak load and energy absorption decreased strongly with increasing loading angle. Kim and Wierzbicki [4] investigated the large planar and biaxial bending rotation response of square cross-section thinwalled beams partially and fully filled with $\mathrm{Al}$ foam. The 
characteristics of moment-rotation responses of the beams were investigated under cantilever bending and found to vary with the lengths of foam fillers. Kim [5] conducted crushing tests on an Al foam-filled front side rail and a sub-frame structure of a passenger car and showed that foam filling increased the energy absorption efficiency. Different from the previous studies, Chen and Nardini [6] investigated crushing behavior of closed-top-hat foamfilled Al sections, including single-top-hat, double-top-hat and double-top-hat with a center plate. It was concluded in the same study that the thin-walled foam-filled members could be used as efficient crash energy absorbers. Seitzberger et al. $[7,8]$ investigated the axial crushing of foam-filled square, hexagonal, octagonal and bitubular steel tubes. It was reported that considerable improvements with respect to energy absorption were obtained with foam filling particularly in bitubular configurations. Chen and Wierzbicki [9] studied the axial crushing of hollow multi-cell columns analytically and numerically. The enhancement in the total crushing resistance of the columns increased, depending on the interaction between the foam filler and the column wall, by the amounts of $140 \%$ and $180 \%$ of the foam filler strength for double- and triple-cell columns, respectively.

In this study, the crushing behavior of several different crash elements composing of empty and foam-filled bitubular and packed Al multi-tubes were investigated experimentally and numerically. Novel multi-tube designs included hexagonal and cubic packing of Al tubes inside rigid cylindrical and rectangular dies. Empty and foam-filled single Al tubes were also tested and modeled for comparison. Closed-cell Al foam was used for the filling of single, bitubular and multi-tubes, while closed-cell polystyrene foam was used to fill the bitubular configurations. The present study is a continuation of the series of studies on the determination of the crushing behavior of empty and foam-filled circular single $\mathrm{Al}$ tubes [10] and multi-tube designs [11] and focuses specifically on the modeling of the empty and foam-filled tubes with bitubular and packed multi-tubes configurations.

\section{Materials and testing}

The deep-drawn Al tubes, received in $25 \mathrm{~mm}(0.29 \mathrm{~mm}$ in wall-thickness) and $35 \mathrm{~mm}(0.35 \mathrm{~mm}$ in wall-thickness $)$ in outer diameter were produced by Metalum Company of Turkey. As-received extruded polystyrene foam sheets with dimensions of $5 \times 60 \times 120 \mathrm{~cm}$ were manufactured by Izocam Company of Turkey. The density of the polystyrene foam was determined by dividing the mass of the cubic foam sample $(5 \times 5 \times 5 \mathrm{~cm})$ by its volume and found to be $0.0321 \pm 0.001 \mathrm{~g} \mathrm{~cm}^{-3}$. The circular polystyrene foam fillers were core-drilled through the thickness of the asreceived foam sheet. The details of the sample preparation and tube filling are given in elsewhere [10]. Al closed-cell foams were prepared using the foaming from powder compacts (precursors) process. Foam plates of $8 \times 8 \mathrm{~cm}$ in cross-section and $3-4 \mathrm{~cm}$ in thickness and having densities ranging between 0.25 and $0.6 \mathrm{~g} \mathrm{~cm}^{-3}$ were prepared. Cylindrical foam samples were then core-drilled normal to the thickness of the plates. The detailed information on the foaming process and foam sample preparation is given in [12]. The density of Al foam filler was determined by simply dividing its weight to its volume.
The crushing behavior of foams samples and foam-filled tubes were determined by compression testing of cylindrical samples, $25 \mathrm{~mm}$ in diameter and $27 \mathrm{~mm}$ in length, using a computer controlled Schimadzu AG-I testing machine at a crosshead speed of $2.5 \mathrm{~mm} \mathrm{~min}^{-1}$. Fig. 1 shows the compression stress-strain responses of the $\mathrm{Al}$ and polystyrene foam fillers. The stress-strain curves of the foams show typical elastoplastic compression behavior, composing of three distinct deformation regions: elastic, collapse (plateau) and densification. As is seen in Fig. 1 the plateau stresses of $\mathrm{Al}$ foams are not constant in the collapse region and increase with increasing strain and foam density. The differences in cell size and cell size distribution cause the collapse of weak cells before the collapse of strong cells, leading to increase in the stress values in collapse region. However, polystyrene foam deforms almost at a constant plateau stress in the collapse region until about 50\% strains as seen in Fig. 1.

Totally 6 main groups of tests were applied to the empty and foam-filled tubes. There were empty and foam-filled single tubes, foam-filled bitubular configurations (3) and empty and foam-filled multi-tube-packed designs (2). Only $25 \mathrm{~mm}$-diameter $\mathrm{Al}$ tubes were filled with $\mathrm{Al}$ foam, while $35 \mathrm{~mm}$-diameter $\mathrm{Al}$ tubes were used to construct bitubular configurations. Three different bitubular configurations were tested. These are shown in Fig. 2a-c and coded as BPH (interior: $25 \mathrm{~mm}$-diameter empty tube and exterior: $35 \mathrm{~mm}$-diameter polystyrene foam-filled tube), BPP (interior: $25 \mathrm{~mm}$-diameter polystyrene foamfilled tube and exterior: $35 \mathrm{~mm}$-diameter polystyrene foam-filled tube) and BPA (interior: $25 \mathrm{~mm}$-diameter $\mathrm{Al}$ foam-filled tube and exterior: $35 \mathrm{~mm}$-diameter polystyrene foam-filled tube). Two tube packing configurations, hexagonal and square, were chosen and tested with empty (Fig. 3a) and foam-filled $25 \mathrm{~mm}$ tubes (Fig. 3b). Square packing consists of four empty and filled tubes (Fig. 3a), while hexagonal packing consists of seven (Fig. 3b). Specially machined cylindrical and rectangular upper compression test platens that fitted closely inside the circular $\mathrm{Al}$ die $(75 \mathrm{~mm}$ in inner diameter, $2.5 \mathrm{~mm}$ in wall thickness and $35 \mathrm{~mm}$ in length) and rectangular steel die $(50 \times 50 \mathrm{~mm}$ in cross-section) were used in the compression testing of the hexagonal- and square-packed empty and filled multi-tubes, respectively. Three groups of hexagonal-packed foam-filled multi-tube designs classified based on the average filler density were tested. These were MHF1 (foam density ranging between 0.4 and $0.47 \mathrm{~g} \mathrm{~cm}^{-3}$ with an average foam density of $0.44 \mathrm{~g} \mathrm{~cm}^{-3}$ ), MHF2 (foam densities ranging between 0.34 and $0.4 \mathrm{~g} \mathrm{~cm}^{-3}$ with an average foam density of $0.38 \mathrm{~g} \mathrm{~cm}^{-3}$ ) and MHF3 (foam densities ranging between 0.51 and $0.6 \mathrm{~g} \mathrm{~cm}^{-3}$ with an average foam density of $0.55 \mathrm{~g} \mathrm{~cm}^{-3}$ ). While two groups of square-packed foam-filled multi-tubes were tested. These were coded as MSF1 and MSF2 with average foam densities of 0.31 and $0.28 \mathrm{~g} \mathrm{~cm}^{-3}$, respectively, were tested. The foam densities in square-packed multi-tube designs ranged between 0.3 and $0.33 \mathrm{~g} \mathrm{~cm}^{-3}$ for the first group and 0.26 and $0.29 \mathrm{~g} \mathrm{~cm}^{-3}$ for the second group of tubes. The length of the tubes in all configurations was $27 \mathrm{~mm}$, determined by the thick-

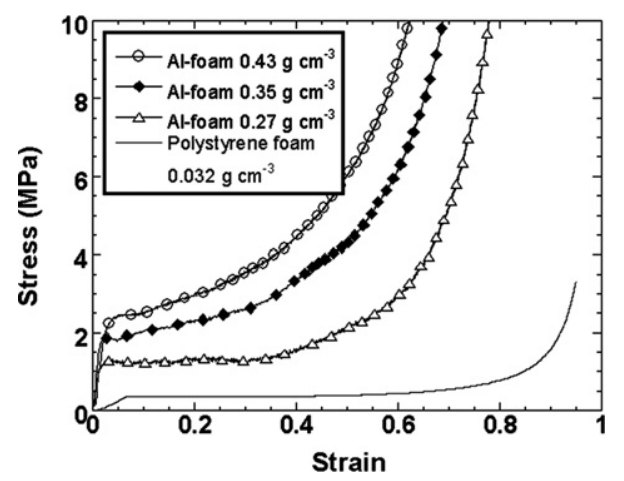

Fig. 1. Compression stress-strain curves of $\mathrm{Al}$ and polystyrene foam fillers. 

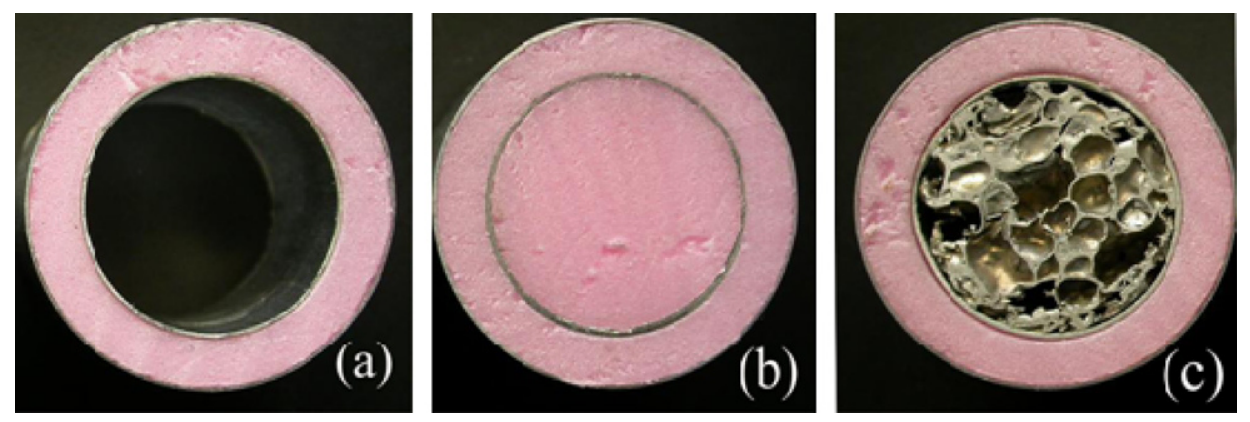

Fig. 2. Bitubular configurations: (a) BPH, (b) BPP and (c) BPA.

nesses of $\mathrm{Al}$ foam plates prepared. All tubes, empty and foam-filled, were compressed at a crosshead speed of $2.5 \mathrm{~mm} \mathrm{~min}^{-1}$ and the corresponding deformation rate of $1.54 \times 10^{-3} \mathrm{~s}^{-1}$.

\section{Modeling}

The geometrical models used in the modeling of the crushing behavior of empty and filled tubes were created in commercial finite element package $\mathrm{ANSYS}^{\mathrm{TM}}$. The meshed geometries were then exported to PAM-GENERIS $^{\mathrm{TM}}$ to set the boundary conditions. The numerical solutions were carried out using the explicit finite element code PAM-CRASH $^{\mathrm{TM}}$ and PAM-VIEW ${ }^{\mathrm{TM}}$ was used as the visualization tool. Detailed information on the modeling procedure is found in [13]. PAM-CRASH ${ }^{\mathrm{TM}}$ provides material model for the metallic cellular solids capable of undergoing large deformation strain including Al foam and Al honeycomb. In this study, the material model of aluminum foam was simplified by replacing the actual behavior with an appropriate equivalent honeycomb having the same properties in three directions (thickness, width and length). The mechanical behavior of metal foams in varying densities was simulated using the following relations:

$$
\begin{aligned}
& E^{*}=E_{\mathrm{S}}\left(\frac{\rho^{*}}{\rho_{\mathrm{S}}}\right)^{2} \\
& G^{*}=0.375 E_{\mathrm{S}}\left(\frac{\rho^{*}}{\rho_{\mathrm{S}}}\right)^{2} \\
& \sigma_{\mathrm{PL}}^{*}=\sigma_{\mathrm{YS}}\left(\frac{\rho^{*}}{\rho_{\mathrm{S}}}\right)^{\frac{3}{2}} \\
& \tau_{\mathrm{PL}}^{*}=0.5 \sigma_{\mathrm{YS}}\left(\frac{\rho^{*}}{\rho_{\mathrm{S}}}\right)^{\frac{3}{2}} \\
& \varepsilon_{\mathrm{D}}=1-1.4 \frac{\rho^{*}}{\rho_{\mathrm{s}}}
\end{aligned}
$$

where, $E, G, \sigma_{\mathrm{Y}}, \tau$ and $\rho$ are the Young's and shear modulus, yield and shear stress and density, respectively. The subscript PL, S and * refer to plateau, foam material and foam, respectively and $\varepsilon_{\mathrm{D}}$ stands for densification strain at which the metal foam begins to densification. Fig. 4 shows the material parameters listed above with corresponding stress-strain curves under compression, tension and shear for the simplified model.

The compression behavior of polystyrene foam material shown in Fig. 1 was modeled using a crushable foam solid material model in PAM-CRASH ${ }^{\mathrm{TM}}$. The elastic behavior
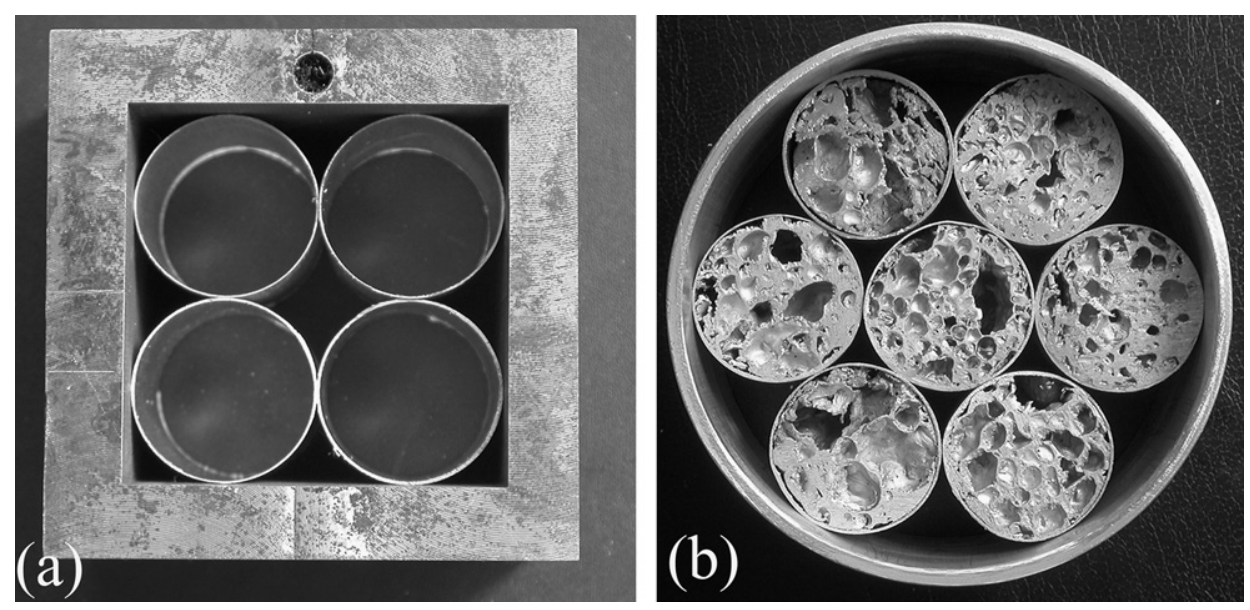

Fig. 3. Packed multi-tube designs: (a) empty square-packed and (b) foam-filled hexagonal-packed tubes. 

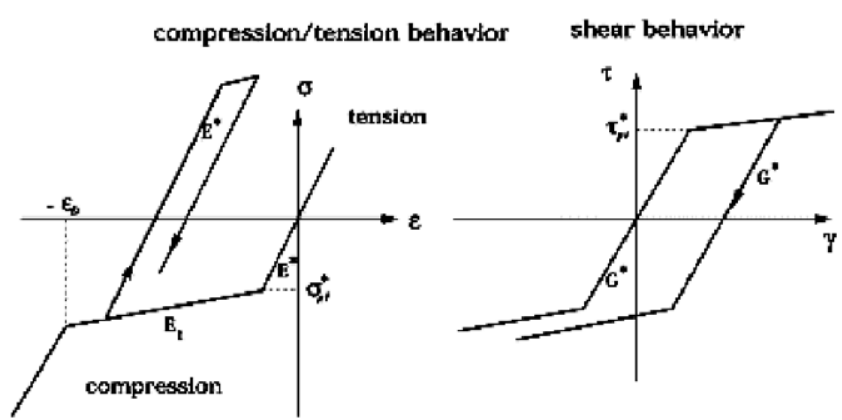

Fig. 4. Material model for aluminum foam.

was described by the shear modulus and the initial tangent modulus. The inelastic behavior exhibited both volumetric (bulk) plasticity and deviatoric (shear) plasticity. The coupling between both parts of the material response is established via a pressure $(p)$ dependent von Mises ( $J_{2}$ plasticity) yield surface.

$\phi_{2}=J_{2}-\left(a_{0}+a_{1} p+a_{2} p^{2}\right)=0$

where $J_{2}=\frac{1}{2} S_{\mathrm{ij}} S_{\mathrm{ij}}=\frac{1}{3} \sigma_{\mathrm{Y}}^{2}$ is the second invariant of the deviatoric stress tensor on the yield surface and $a_{0}, a_{1}$ and $a_{2}$ are the user specified material parameters linked to the user specified pressure cut-off for tensile fracture.

The polystyrene foam filling between $25 \mathrm{~mm}$-inner and $35 \mathrm{~mm}$-outer tubes as well as the interaction region between the tube wall and the foam filler in BPP design (Fig. 2b) was modeled using Smooth Particle Hydrodynamics (SPH). SPH method is based on two interpolation approximations: kernel and particle approximation. Considering the function $f(x)$ in Eq. (7), the value at a point of $f(x)$ over the domain $\Omega$ could be extracted from its integral using the delta $(\delta)$ function given in Eq. (8) as a filter,

$\langle f(\bar{x})\rangle=\int_{\Omega} f\left(\overline{x^{\prime}}\right) \delta\left(\bar{x}-\overline{x^{\prime}}\right) \mathrm{d} \overline{x^{\prime}}$

and

$\int_{\Omega} \delta\left(\bar{x}-\overline{x^{\prime}}\right) \mathrm{d} \overline{x^{\prime}}=1$

As $h \rightarrow 0, \delta\left(\bar{x}-\bar{x}^{\prime}\right)$ can be replaced with a kernel function of $W\left(\bar{x}-\overline{x^{\prime}}, h\right)$, which has a support domain determined by the parameter $h$,

$\lim _{h \rightarrow 0} W\left(\bar{x}-\bar{x}^{\prime}, h\right)=\delta\left(\bar{x}-\overline{x^{\prime}}\right)$

Inserting Eq. (9) into Eq. (7) gives the following equation:

$\langle f(\bar{x})\rangle=\int_{\Omega} f\left(\overline{x^{\prime}}\right) W\left(\bar{x}-\bar{x}^{\prime}, h\right) \mathrm{d} \overline{x^{\prime}}$

Since, domain is represented by discrete particles, the summation of the contributions of each particle within the kernel approximation range gives the smoothed value of $f(x)$ at a point (particle approximation) as,
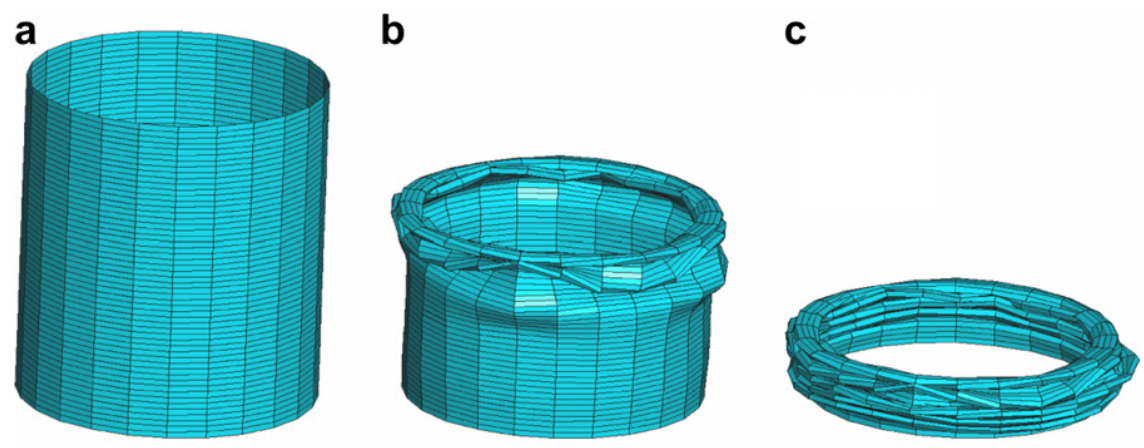

Fig. 5. Images of crushed 25 mm-diameter Al tube at (a) $0 \%$, (b) $40 \%$ and (c) $80 \%$ strains.
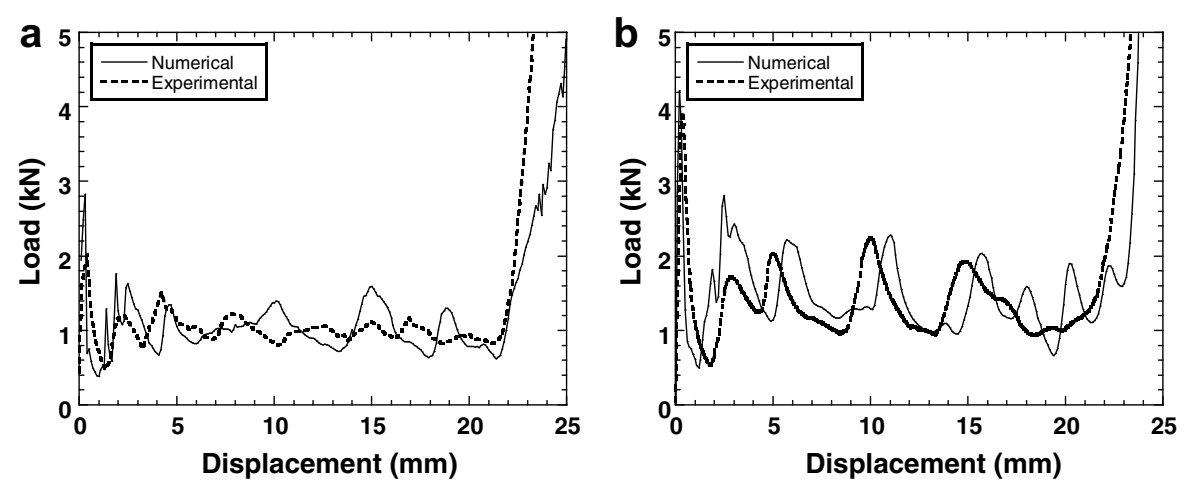

Fig. 6. Numerical and experimental load-displacement curve of (a) $25 \mathrm{~mm}$ - and (b) $35 \mathrm{~mm}$-diameter empty tubes. 

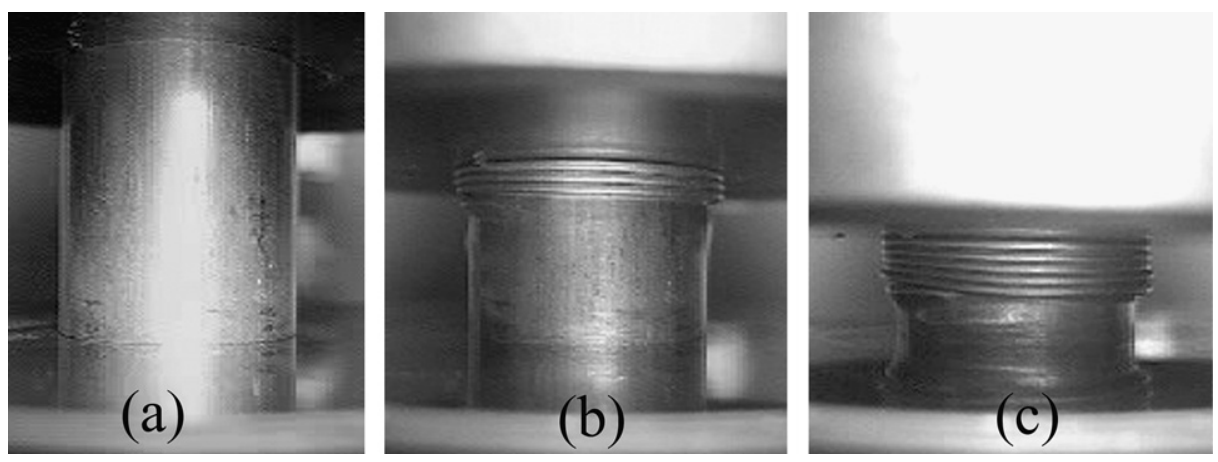

Fig. 7. Images of crushed $25 \mathrm{~mm}$-diameter $\mathrm{Al}$ foam-filled $\left(0.27 \mathrm{~g} \mathrm{~cm}^{-3}\right)$ tube at (a) $0 \%$, (b) $40 \%$ and (c) $70 \%$ strain.

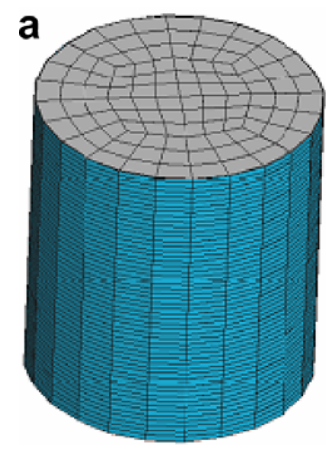

b

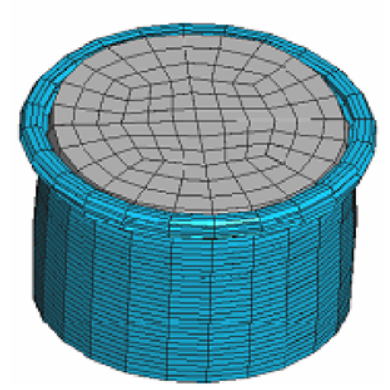

C

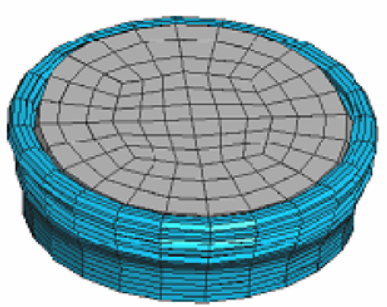

Fig. 8. Numerical images of crushed $\mathrm{Al}$ foam-filled $\left(0.27 \mathrm{~g} \mathrm{~cm}^{-3}\right)$ tube at (a) $0 \%$, (b) $40 \%$ and (c) $70 \%$ strain.
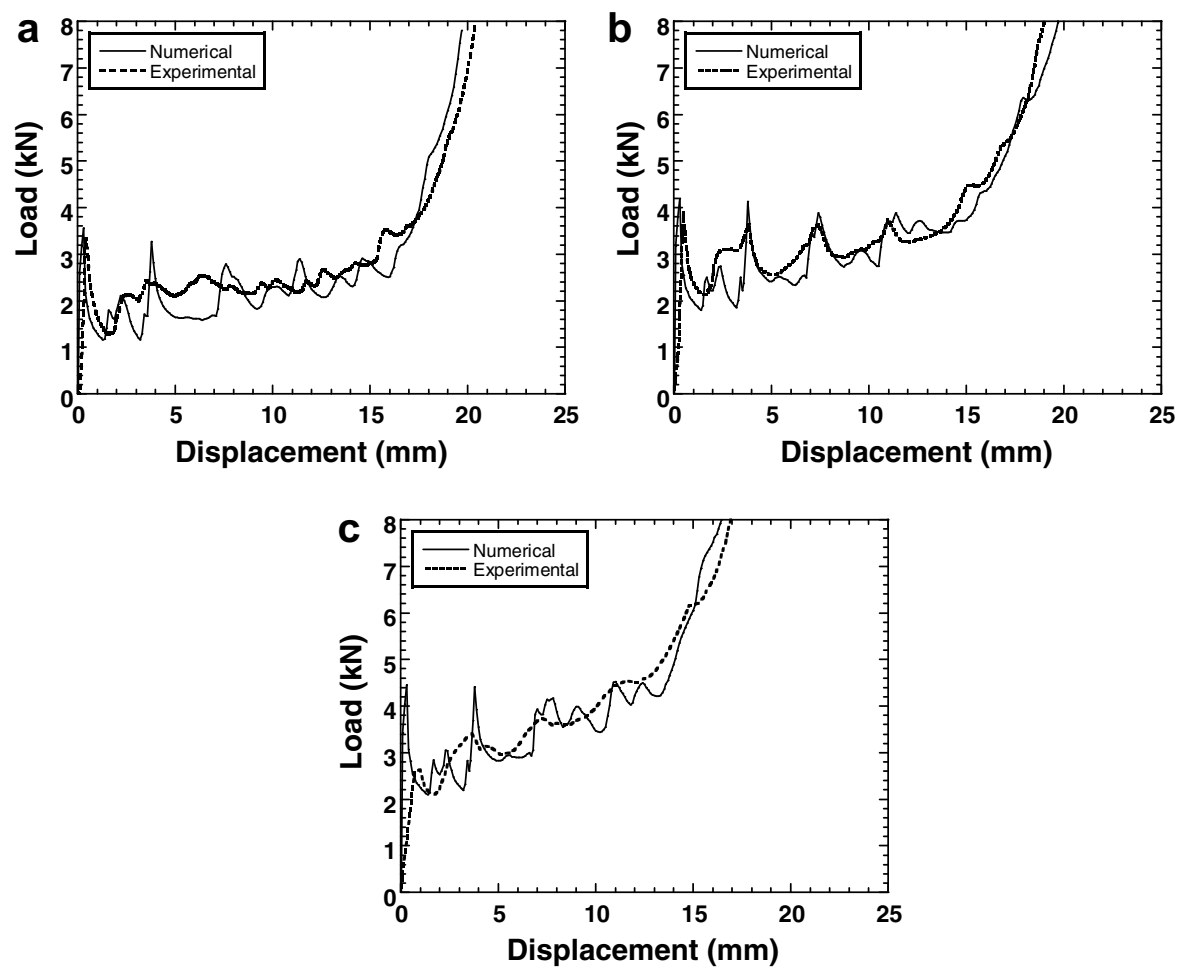

Fig. 9. Numerical and experimental load-displacement curves of (a) 0.27 , (b) 0.35 and (c) $0.43 \mathrm{~g} \mathrm{~cm}^{-3} \mathrm{Al}$ foam-filled $25 \mathrm{~mm}$ tubes.

$\langle f(\bar{x})\rangle=\sum_{j=1}^{N}\left(\frac{m_{j}}{\rho_{j}}\right) f_{j} W\left(\left|\bar{x}-\overline{x^{\prime}}\right|, h\right)$ where, $N$ represents the number of discrete particles and $m_{j}$ and $\rho_{j}$ are the mass and density of the particle $j$, respectively. Localization and information transformation from 
one particle to another are achieved through an interpolation distance called the smoothing length. The sphere of influence of a particle is a multiple of its smoothing length.

The material model used for discrete SPH particles was an isotropic-elastic-plastic-hydrodynamics solid material model, of which an Equation of State was used to model the pressure-volume relation as,

$p=C_{0}+C_{1} \mu+C_{2} \mu^{2}+C_{3} \mu^{3}$

where, $C_{0}, C_{1}, C_{2}, C_{3}$ are the material constants and $\mu$ is a dimensionless compressibility parameter which depends on the current density $(\rho)$ and initial density $\left(\rho_{0}\right)$ as,

$\mu=\frac{\rho}{\rho_{0}}-1$

The polynomial form of the equation is a widely used approximation for many materials and it reduces, when $\mathrm{C}_{0}=\mathrm{C}_{2}=\mathrm{C}_{3}=0$, to a dilatational elastic material law with bulk modulus of $C_{1}$ [14]. Discrete particles were generated with a simple transformation of finite element mesh into mass points.

\section{Results and discussion}

\subsection{Single empty tubes}

Empty tubes both 25 and $35 \mathrm{~mm}$ in diameter deformed in progressive diamond mode forming eight-corner folding geometry. Fig. 5 shows the numerically obtained deformation patterns of $25 \mathrm{~mm}$-diameter tube at 0,40 and $80 \%$ strains. It has been experimentally found and numerically confirmed that 4-5 folds formed in both empty tubes. Typical numerical and experimental load-displacement curves of the tubes are shown in Fig. 6a and b for 25 and $35 \mathrm{~mm}$-diameter tubes, respectively. Despite to the differences between the displacements corresponding the to the peak loads, numerical and experimental load values are relatively comparable and show well agreements with each other. It is also noted in Fig. 6a and b that numerical and experimental initial peak load values are greater than those of following peak loads. This is a phenomenon commonly observed in thin-wall tube crushing, which simply arises from the constraining effect imposed by the compression test platens.

\subsection{Foam-filled single tubes}

The effect of $\mathrm{Al}$ foam filling of $25 \mathrm{~mm}$-diameter empty Al tube is to shift the deformation mode from diamond to progressive axisymmetric (concertina) mode of deformation, regardless the $\mathrm{Al}$ foam density $(0.27,0.35$ and $0.43 \mathrm{~g} \mathrm{~cm}^{-3}$ ) used for filling. The number of folds formed also increased with $\mathrm{Al}$ foam filling from 4 in empty tube to 6 in filled tube and hence the fold length decreased accordingly. Figs. 7 and 8 show experimental and numerical concertina mode of deformation of $25 \mathrm{~mm}$-diameter tube filled with $0.27 \mathrm{~g} \mathrm{~cm}^{-3} \mathrm{Al}$ foam at $0 \%, 40 \%$ and $70 \%$ strains, respectively. The numerical and experimental load-displacement curves for $\mathrm{Al}$ foam-filled tubes at three different foam densities are shown in Fig. 9a-c. Numerical deformation patterns and load values of filled tubes show relatively well agreements with those of experiments as shown in Figs. 7-9.

\subsection{Foam-filled bitubular tubes}

In investigated bitubular configurations, BPH, BPP and $\mathrm{BPA}$, the outer $35 \mathrm{~mm}$-diameter tube deformed in diamond mode (Fig. 10a-c) similar to empty tubes. The inner $25 \mathrm{~mm}$-diameter tube deformed in diamond mode in BPH and concertina mode in BPP and BPA configurations, showing again the thickening effect of the foam filling. It is also noted in Fig. 1 that the polystyrene foam filler experiences low values of compression stresses than aluminium foam at the same strain level. For this reason the polysty-

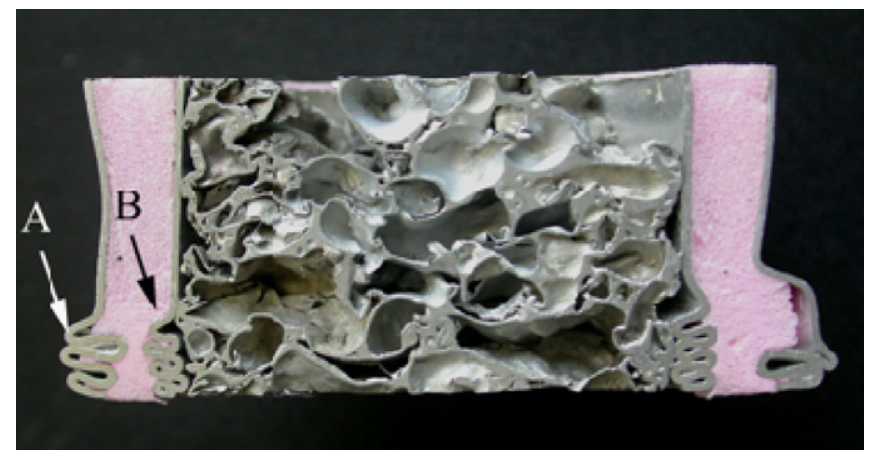

Fig. 11. Side view of crushed BPA specimen.
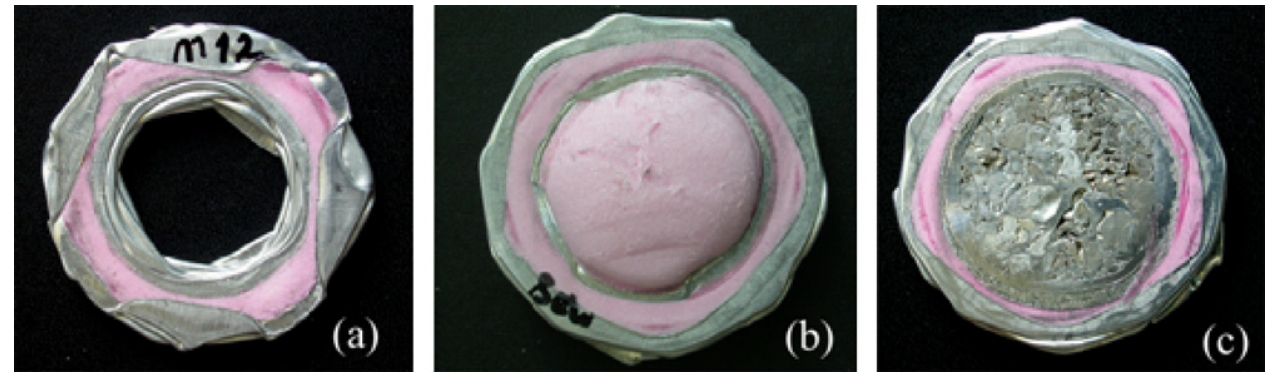

Fig. 10. Top view of deformed (a) BPH, (b) BPP and BPA bitubular configurations. In (a) both tubes deformed in diamond mode, while interior tube deformed in concertina mode in (b) and (c). 

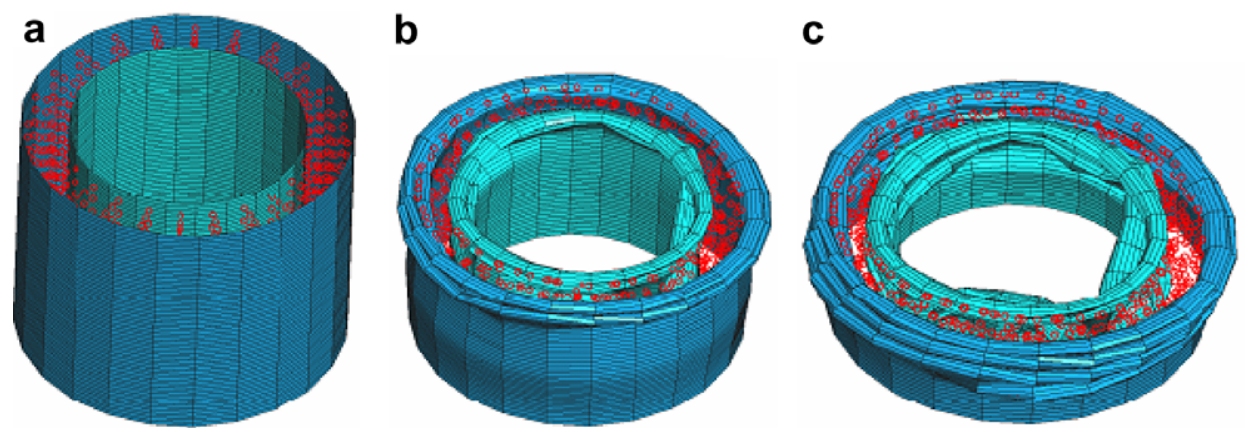

Fig. 12. Numerical images of crushed BPH design at (a) $0 \%$, (b) $40 \%$ and (c) $65 \%$ strains.
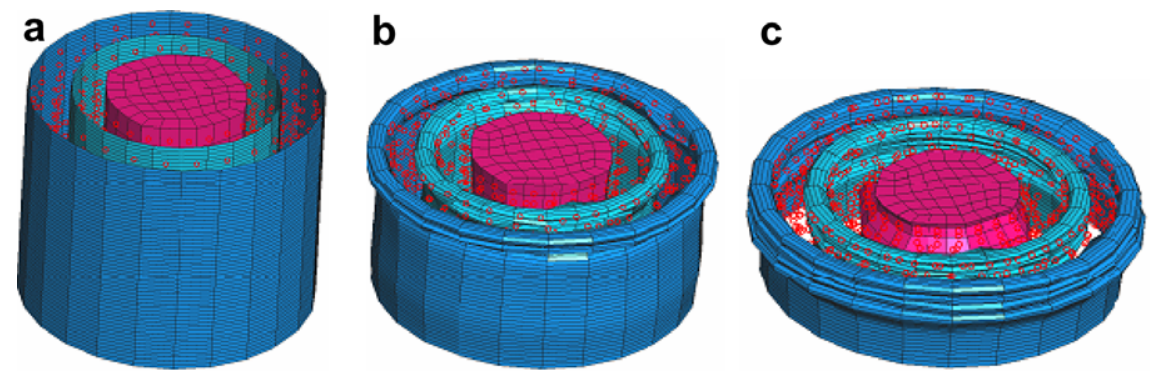

Fig. 13. Numerical images of crushed BPP design at (a) $0 \%$, (b) $35 \%$ and (c) $65 \%$ strains.

rene foam filler shows comparably larger deformations particularly near to the folded tube wall (A in Fig. 11) than $\mathrm{Al}$ foam filler (B in Fig. 11). Therefore, the discrete particles were used to model the extensive deformation zones of polystyrene foam filler in bitubular configurations. Figs. 12-14 show the numerical deformation patterns of the $\mathrm{BPH}, \mathrm{BPP}$ and BPA configurations, respectively. The experimental deformation patterns are seen in these figures reproducible with the proposed numerical coupled model. The experimental and numerical number of folds also shows well coincidence. The experimental number of folds is the same for the three configurations, 4 , while the numerical fold numbers are 5, 4 and 4 for BPH, BPP and BPA, respectively. The comparison between numerical and experimental load-displacement curves of BPH, BPP and BPA configurations are shown sequentially in Fig. 15a-c. Although, the first load-peak values of the numerical load-displacement curves are higher than those of experimental values, the following load values are very similar.
It is assumed that the foam fillers have the same strength values in three orthogonal directions in the modeling, but the anisotropy in strength values of the filler exists due to the variations in the cell size and cell wall-thicknesses. This inevitably results in discrepancies between the numerical model and experimental results.

\subsection{Empty and foam-filled packed multi-tubes}

Similar to single empty tubes, hexagonal-(coded as MHE) and square-(coded as MSE) packed empty multitubes deformed in diamond mode as shown sequentially in Figs. 16a and 17a. The numerical deformation patterns of MHE and MSE designs are also shown in Figs. 16b and $17 \mathrm{~b}$, respectively and reflect the essential experimental deformation characteristics of the multi-tube deformations in each design. The tubes of hexagonal packing contacting the mold wall deform in elliptical while the central tube deformed in hexagonal shape as seen in Fig. 16a and b.
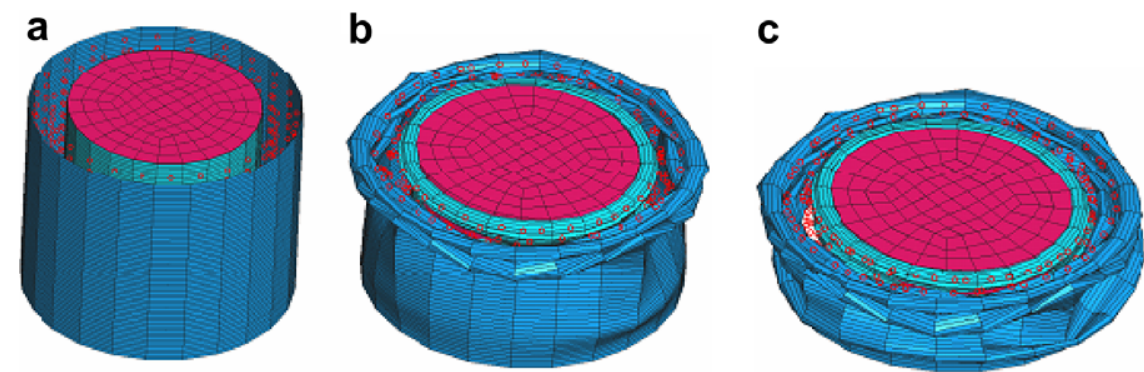

Fig. 14. Numerical images of crushed BPA design at (a) $0 \%$, (b) $40 \%$ and (c) $65 \%$ strains. 

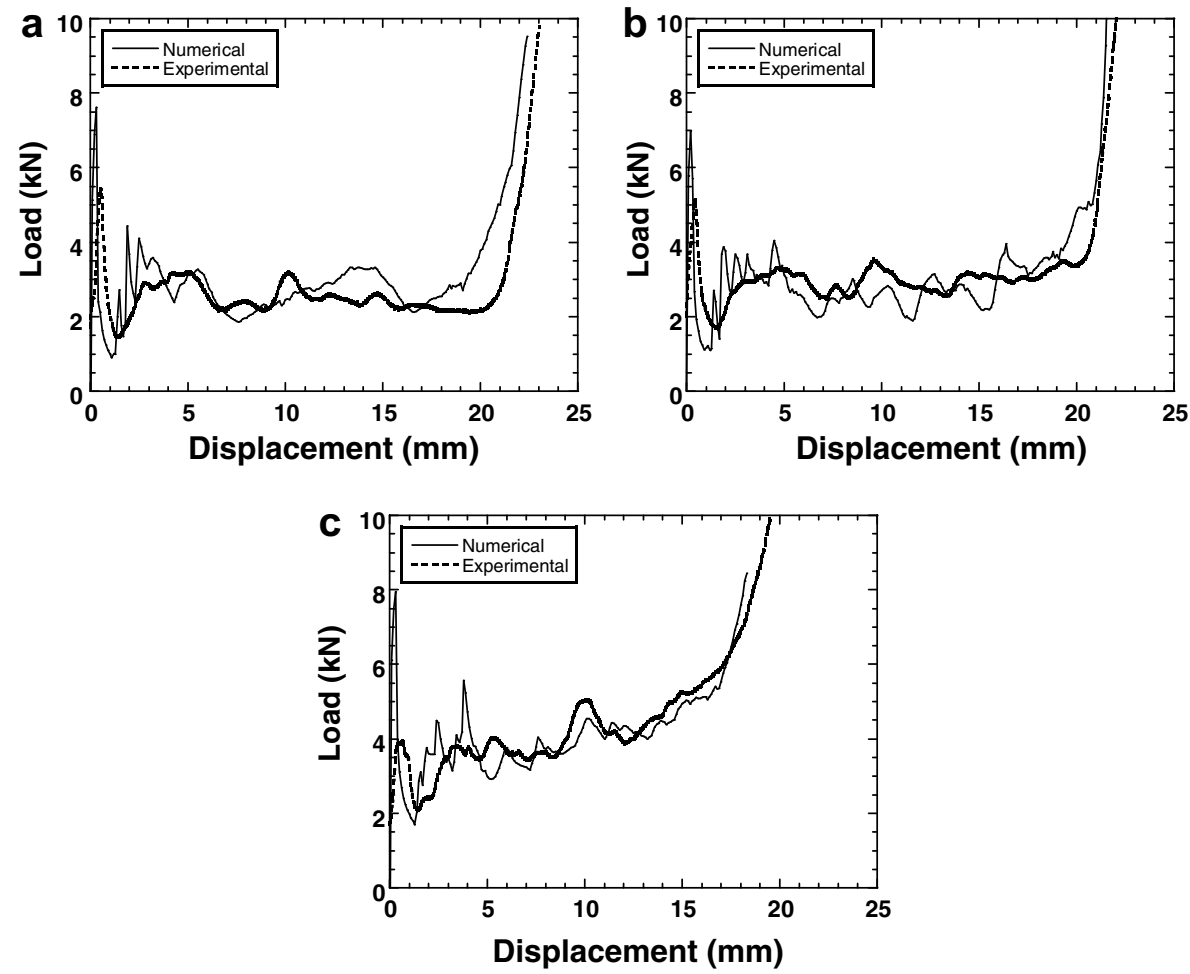

Fig. 15. Numerical and experimental load-displacement curves of (a) BPH, (b) BPP and (c) BPA designs.
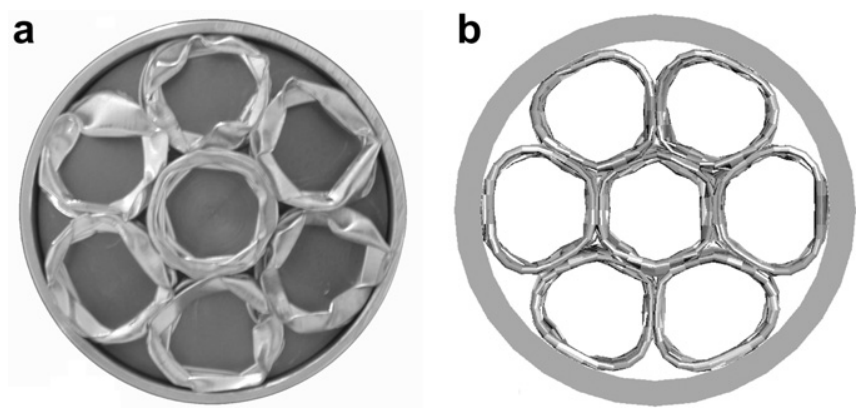

Fig. 16. Crushed MHE tube design: (a) experimental and (b) numerical.

In the square packing of empty tubes, experimental and numerical deformations result in similar final deformation shapes in that tubes become square in cross-section as depicted in Fig. 17a and b. In MHE and MSE designs totally 4-5 folds formed, same with those of the models. It is also noted in Figs. 16 and 17 numerical models result in more regular deformation patterns as compared with experiments. In experiments the initial folding is naturally effected by the flatness of the tube surfaces and by the artifacts, which likely induce irregular patterns of diamond mode of deformation.

Similar to Al foam-filled single tube the foam filling in multi-tube designs results in a change in the deformation mode from diamond to concertina mode (Figs. 18a and 19a). The models shown in Figs. 18 b and 19 b also show similar deformation shapes with those of experiments shown in Figs. 18a and 19a. In foam-filled hexagonal
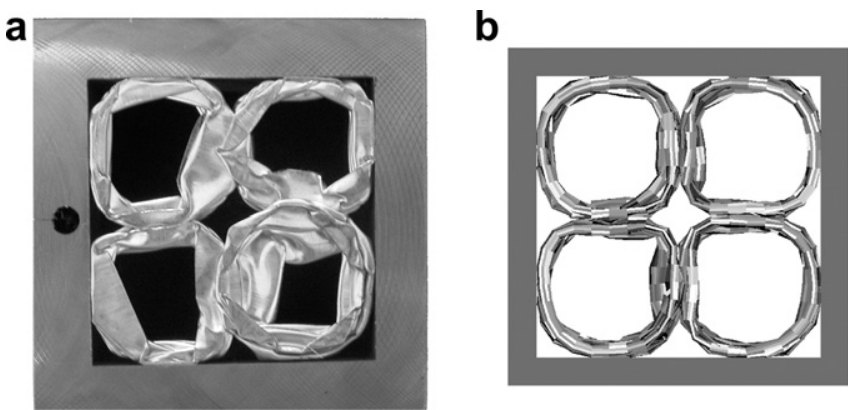

Fig. 17. Crushed MSE design: (a) experimental and (b) numerical.

multi-tube designs, totally $6-7$ folds formed. The numerically obtained number of folds was $6,6-7$ and 6 for MHF1, MHF2 and MHF3, respectively. The numerical number of folds also showed well agreement with that of experiments in square-packed tubes. The experimental number of folds was 7-8 for MSF1 and 6-7 for MSF2. The numerical number of folds was 7 for MSF1 and MSF2.

The experimental and numerical load-displacement curves of hexagonal- and square-packed empty and foam-filled tubes are shown sequentially in Fig. 20a-d for MHE, MHF1 (av. Al foam density: $0.44 \mathrm{~g} \mathrm{~cm}^{-3}$ ), MHF2 (av. Al foam density: $0.38 \mathrm{~g} \mathrm{~cm}^{-3}$ ) and MHF3 (av. Al foam density: $0.55 \mathrm{~g} \mathrm{~cm}^{-3}$ ) and in Fig. 21a-c for MSE, MSF1 (av. Al foam density: $0.31 \mathrm{~g} \mathrm{~cm}^{-3}$ ) and MSF2 (av. $\mathrm{Al}$ foam density: $0.28 \mathrm{~g} \mathrm{~cm}^{-3}$ ). As noted in these figures, as the average density of $\mathrm{Al}$ foam filler in multi-tubes increases the 
a

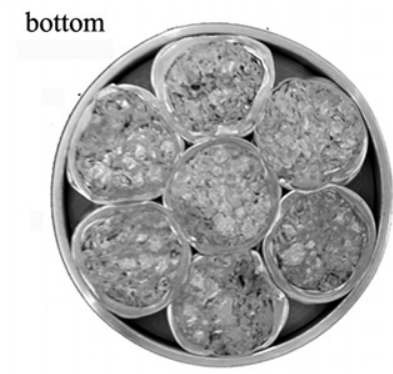

b
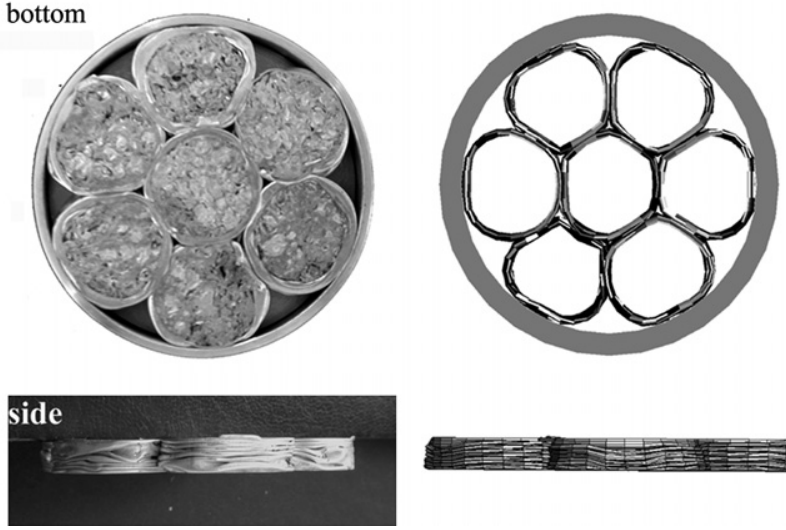

Fig. 18. Bottom and side views of crushed MHF design (a) experimental and (b) numerical.

load values increase. The average crushing load of single empty $25 \mathrm{~mm}$-diameter $\mathrm{Al}$ tube was previously determined [10]. The measured average crushing loads of empty tube designs, both MHE and MSE were found greater than the sum of the average crushing loads of the equal number of single empty tubes. The increase in average crushing load of multi-tube designs of empty tubes are $0.92 \mathrm{kN}$ for MHE and $0.4 \mathrm{kN}$ for MSE designs. The increase in the average crushing loads of packed empty tubes over the equal number of single empty tubes was also confirmed numerically for both designs. The increase in average a

bottom
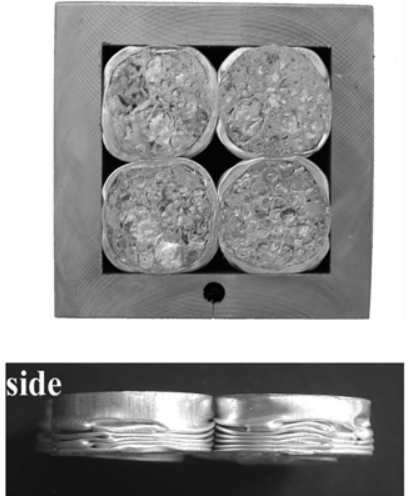

b
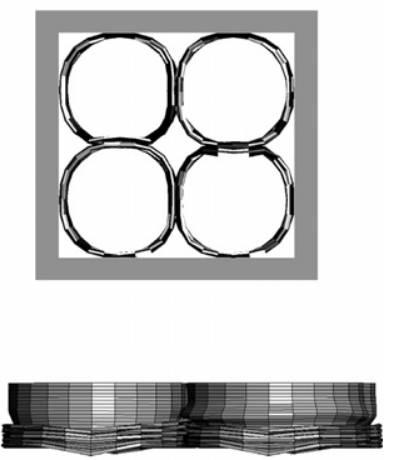

Fig. 19. Bottom and side views of crushed MSF design (a) experimental and (b) numerical.

crushing loads of empty multi-tube designs simply a result of frictional forces between tubes and tube walls and the die wall and the constraining effect of the die wall. The effect is however greater in MHE due to a large surface area of tubes touch to each other and to the surfaces of the die wall.

\subsection{Comparison of $S A E$ values}

The experimental and numerical SAE values of the investigated empty and foam-filled single, bitubular and
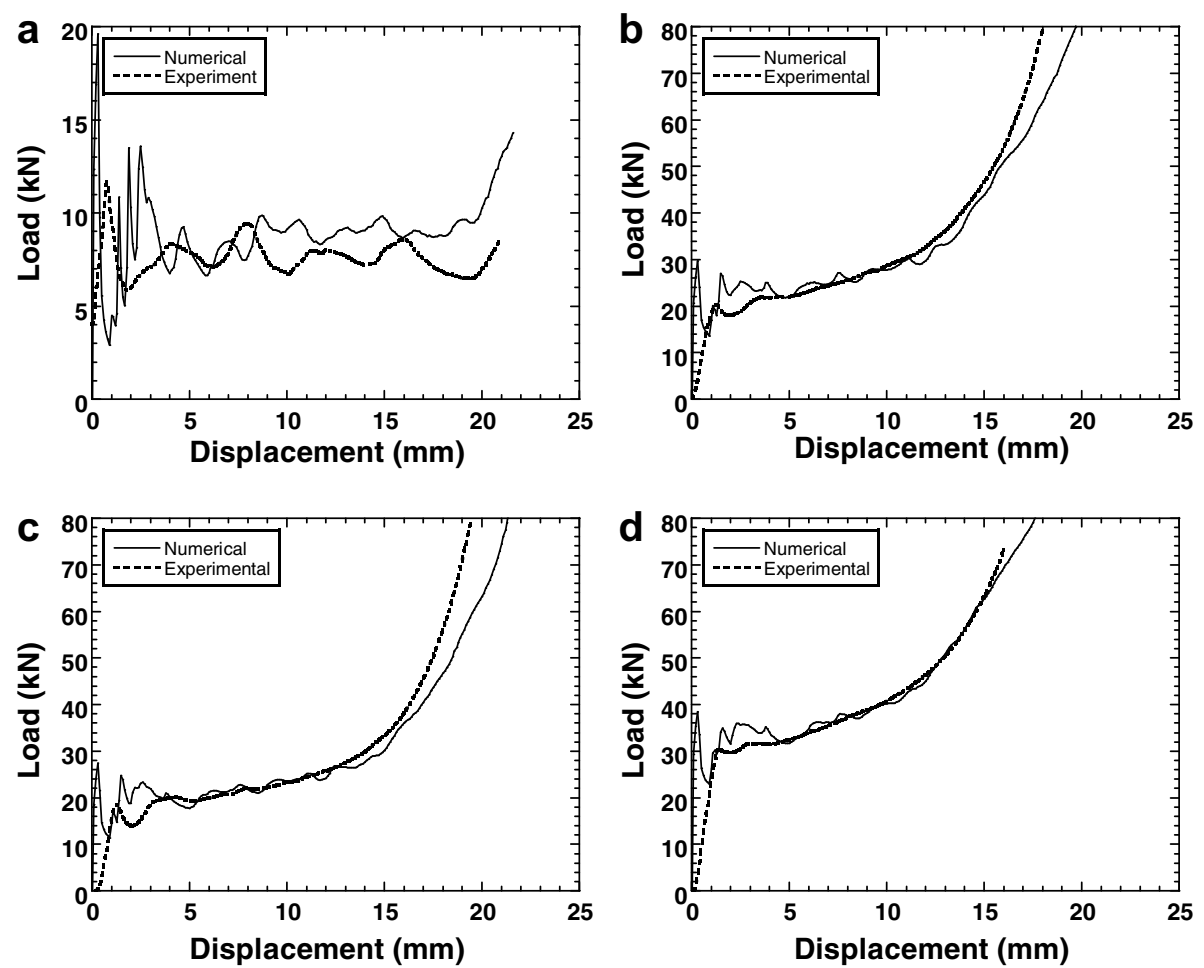

Fig. 20. Numerical and experimental load-displacement curves of (a) MHE, (b) MHF1, (c) MHF2 and (d) MHF3 designs. 

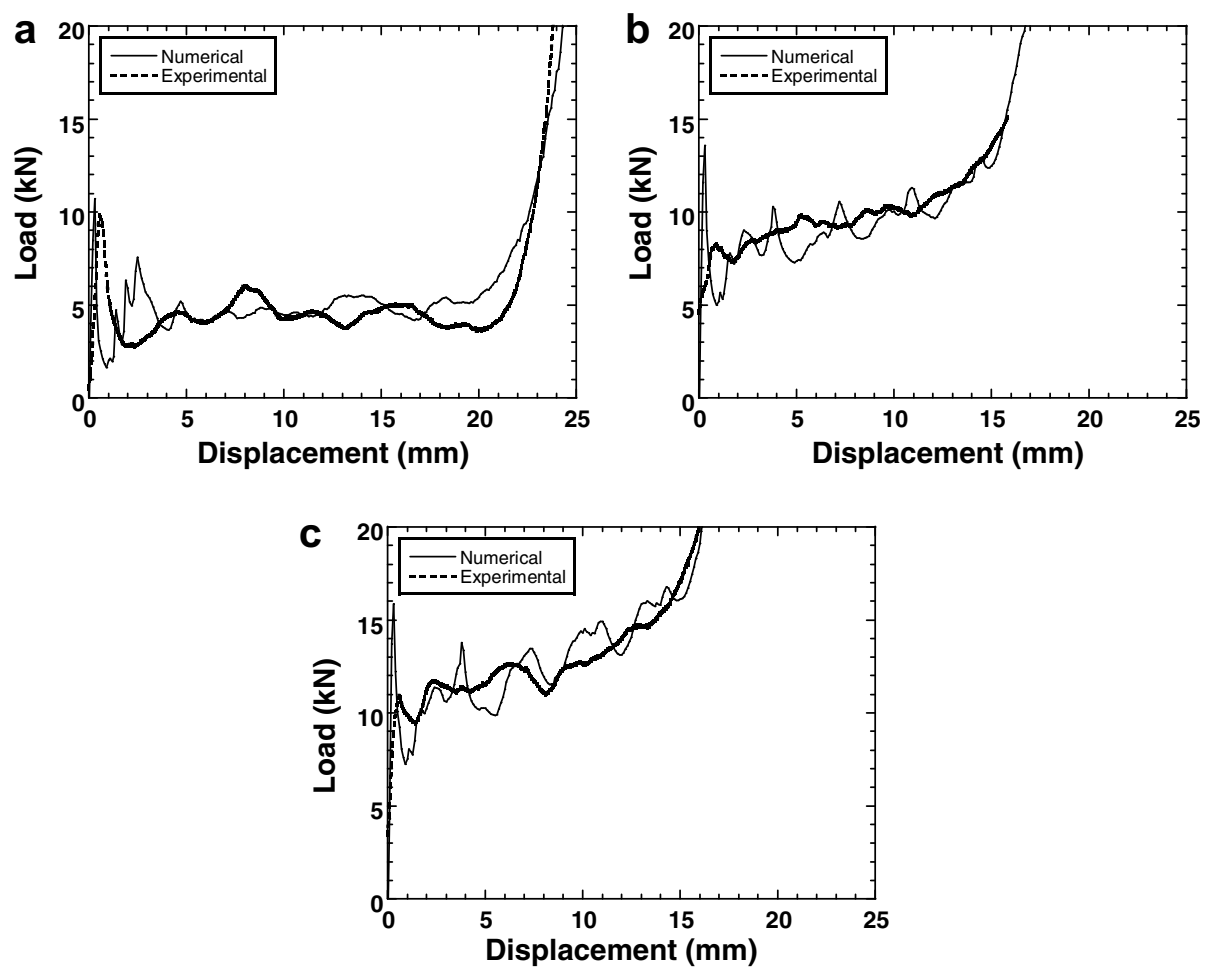

Fig. 21. Numerical and experimental load-displacement curves of (a) MSE, (b) MSF1 and (c) MSF2 designs.

packed multi-tubes corresponding to $50 \%$ deformation are tabulated in Table 1. The maximum difference between the experimental and numerical SAE values in Table 1 is about $10 \%$. The experimental SAE values listed in this table show that multiple-packed empty tubes (MHE and MSE) and single empty tube absorb more energy than foam-filled single, bitubular and foam-filled multiple tubes. However, multiple empty tubes show higher experimental and numerical SAE values than that of empty single tube. This is mainly due to the frictional effects of die wall and interac-

Table 1

Experimental and numerical SAE values of empty and foam-filled tubes at $50 \%$ strain

\begin{tabular}{llll}
\hline Design & $\begin{array}{l}\text { Foam filler density } \\
\left(\mathrm{g} \mathrm{cm}^{-3}\right) \mathrm{P}: \\
\text { polystyrene } \\
\text { A: aluminum }\end{array}$ & $\begin{array}{l}\text { Experimental } \\
\mathrm{SAE}\left(\mathrm{kJ} \mathrm{kg}^{-1}\right)\end{array}$ & $\begin{array}{l}\text { Numerical } \\
\mathrm{SAE}\left(\mathrm{kJ} \mathrm{kg}^{-1}\right)\end{array}$ \\
& - & & \\
\hline Empty & & 8.21 & 7.83 \\
Filled single tube & $0.27(\mathrm{~A})$ & 5.57 & 5.11 \\
Filled single tube & $0.35(\mathrm{~A})$ & 6.69 & 6.14 \\
Filled single tube & $0.43(\mathrm{~A})$ & 6.16 & 6.24 \\
BPH & $0.0321(\mathrm{P})$ & 7.38 & 7.09 \\
BPA & $0.0321(\mathrm{P}) 0.35(\mathrm{~A})$ & 5.82 & 5.12 \\
BPP & $0.0321(\mathrm{P})$ & 7.35 & 6.95 \\
MSE & - & 8.80 & 8.71 \\
MSF1 & $0.3-0.33(\mathrm{~A})$ & 7.21 & 6.85 \\
MSF2 & $0.26-0.3(\mathrm{~A})$ & 5.96 & 5.57 \\
MHE & - & 8.62 & 9.23 \\
MHF1 & $0.4-0.47(\mathrm{~A})$ & 6.94 & 6.54 \\
MHF2 & $0.34-0.4(\mathrm{~A})$ & 6.04 & 6.25 \\
MHF3 & $0.5-0.6(\mathrm{~A})$ & 7.89 & 7.87 \\
\hline
\end{tabular}

tions between the tubes in the multi-tube designs. Although, experimentally square-packed empty tube design shows slightly higher SAE value than hexagonalpacked empty tube design, numerically hexagonal-packed empty tube designs have higher SAE values. The discrepancy between numerical and experimental results will be further investigated.

The SAE values of $\mathrm{Al}$ foam-filled single and bitubular tubes are found to be lower than that of empty tube until about large strains. As the crash absorbers undergo large deformations, the foam filling of single, bitubular and multi-tubes designs become energetically more efficient

Table 2

Experimental and numerical SAE values of empty and foam-filled tubes at $80 \%$ strain

\begin{tabular}{lll}
\hline Design & $\begin{array}{l}\text { Experimental SAE } \\
\left(\mathrm{kJ} \mathrm{kg}^{-1}\right)\end{array}$ & $\begin{array}{l}\text { Numerical SAE } \\
\left(\mathrm{kJ} \mathrm{kg}^{-1}\right)\end{array}$ \\
\hline $\begin{array}{l}\text { Empty tube } \\
\text { Al foam-filled single tube }\end{array}$ & 12.7 & 12.39 \\
$\left.\quad 10.27 \mathrm{~g} \mathrm{~cm}^{-3}\right)$ & 13.17 \\
$\begin{array}{l}\text { Al foam-filled single tube } \\
\quad\left(0.35 \mathrm{~g} \mathrm{~cm}^{-3}\right)\end{array}$ & 16.78 & 14.89 \\
Al foam-filled single tube & 18.86 & \\
$\quad\left(0.43 \mathrm{~g} \mathrm{~cm}^{-3}\right)$ & & 19.16 \\
BPH & 11.36 & 11.97 \\
BPP & 12.28 & 12.75 \\
BPA & 13.43 & 12.93 \\
MSE & 13.9 & 14.62 \\
MHE & 13.63 & 16.66 \\
\hline
\end{tabular}


Table 3

Experimental and numerical SAE values of $\mathrm{Al}$ foam-filled single and multi- tube designs at $60 \%$ strain

\begin{tabular}{lllll}
\hline SAE $\left(\mathrm{kJ} \mathrm{kg}^{-1}\right)$ & $\begin{array}{l}\text { Al foam-filled single } \\
\text { tube }\left(0.27 \mathrm{~g} \mathrm{~cm}^{-3}\right)\end{array}$ & MSF2 $\left(0.26-0.30 \mathrm{~g} \mathrm{~cm}^{-3}\right)$ & $\begin{array}{l}\text { Al foam-filled } \\
\text { single tube }\left(0.43 \mathrm{~g} \mathrm{~cm}^{-3}\right)\end{array}$ & $\begin{array}{l}\text { MHF1 } \\
\left(0.40-0.47 \mathrm{~g} \mathrm{~cm}^{-3}\right)\end{array}$ \\
\hline Experimental & 6.96 & 7.54 & 8.15 & 9.38 \\
Numerical & 6.49 & 7.19 & 8.47 & 8.73 \\
\hline
\end{tabular}

compared with single empty tube. As is tabulated in Table 2 the experimental and numerical SAE values of Al foam-filled single tubes and BPA bitubular designs exceed the single empty tube SAE value at $80 \%$ strain. The increase of SAE values of filled tubes over that of empty tube is mainly to the increase of the foam density with increasing deformation strain. It was previously shown that there is a critical foam density above which the foam filling became more efficient [1]. The critical foam filler density therefore reached during the deformation of the foam-filled tubes. It is also seen in Table 3 that foam-filled multi-tube designs show higher SAE values than those of foam-filled single tubes at similar foam densities, which is again pronouncing the effect interactions between tubes and tubes and die wall in multi-tube designs.

\section{Conclusions}

In this study the quasi-static crushing behavior of $\mathrm{Al}$ and polystyrene foam-filled single, bitubular and multitube configurations were compared through compression testing and numerical analysis. Tubes and foam fillers were modeled using Finite Element and coupled Finite Element/ Smooth Particle Hydrodynamics. In all tested and modeled configurations $\mathrm{Al}$ foam filling changed the deformation mode from diamond into concertina. Single empty Al tube showed higher SAE values than $\mathrm{Al}$ foam-filled single tubes, $\mathrm{Al}$ and polystyrene foam-filled bitubular configurations and $\mathrm{Al}$ foam-filled multi-tube configurations, while hexagonal- and square-packed empty multi-tube designs showed increased SAE values as compared with single empty tube. The increase in SAE values was even greater in modeling in hexagonal- than square-packed design due to more contact surfaces between adjacent tubes, tube walls and die wall. Although, the foam filling in multi-tube designs was found to be not effective in increasing the SAE values over that of empty tube, foam-filled multi-tube geometries were energetically more efficient than $\mathrm{Al}$ foam-filled single tubes for both hexagonal- and square-packed geometries at similar and studied foam filler densities. This was again attributed to the frictional loads of the multi-tube designs and constraining effect of the die walls. Finally, it was shown that the experimental results have shown well accordance with the numerical results.

\section{Acknowledgements}

The authors thank Scientific and Technical Council of Turkey (TUBITAK) for the Grant No. MISAG-227 and Dr. Alastair F. Johnson (German Aerospace Center) for valuable discussions.

\section{References}

[1] Santosa S, Wierzbicki T. Crash behavior of box columns filled with aluminum honeycomb or foam. Comput Struct 1998;68:343-67.

[2] Santosa S, Wierzbicki T. Effect of an ultralight metal filler on the bending collapse behavior of thin-walled prismatic columns. Int $\mathrm{J}$ Mech Sci 1999;41:995-1019.

[3] Børvik T, Hopperstad OS, Reyes A, Langseth M, Solomos G, Dyngeland T. Empty and foam-filled circular aluminium tubes subjected to axial and oblique quasi-static loading. Int $\mathbf{J}$ Crashworth 2003;8:481-94.

[4] Kim HS, Wierzbicki T. Biaxial bending collapse of thin-walled beams filled partially or fully with aluminum foam. Int $\mathbf{J}$ Crashworth 2000;5:363-80.

[5] Kim HS. Analysis of crash response of aluminum foam-filled front side rail of a passenger car. Int J Crashworth 2001;2:189-207.

[6] Chen W, Nardini D. Experimental study of crush behavior of sheet aluminium foam-filled sections. Int $\mathbf{J}$ Crashworth 2000;5:447-68.

[7] Seitzberger M, Rammerstorfer FG, Degischer HP, Gradinger R. Crushing of axially compressed steel tubes filled with aluminum foam. Acta Mech 1997;125:93-105.

[8] Seitzberger M, Rammerstorfer FG, Gradinger R, Degischer HP, Blaimschein M, Walch C. Experimental studies on the quasi-static axial crushing of steel columns filled with aluminum foam. Int $\mathbf{J}$ Solids Struct 2000;37:4125-47.

[9] Chen W, Wierzbicki T. Relative merits of single-cell, multi-cell and foam-filled thin-walled structures in energy absorption. Thin-Walled Struct 2001;39:287-306.

[10] Toksoy AK, Guden M. The strengthening effect of polystyrene foam filling in aluminum thin-walled cylindrical tubes. Thin-Walled Struct 2005;43:333-50.

[11] Guden M, Kavi H. Quasi-static axial compression behavior of constraint hexagonal and square-packed empty and aluminum foamfilled aluminum multi-tubes. Thin-Walled Struct 2006;44:739-50.

[12] Guden M, Yuksel S. Compression behavior of SiC-particulate foams produced by foaming from powder compacts. J Mater Sci 2006;41:4075-84.

[13] Aktay L, Toksoy AK, Guden M. Quasi-static axial crushing of extruded polystyrene foam-filled thin-walled aluminum tubes: experimental and numerical analysis. Mater Design 2006;27:556-65.

[14] Hiermaier S, Thoma K. Computational simulation of high velocity impact simulations using smoothed particle hydrodynamics. In: Nineth DYMAT technical conference on materials and structural modelling in collosion research, TU Munich, Germany 1995. 